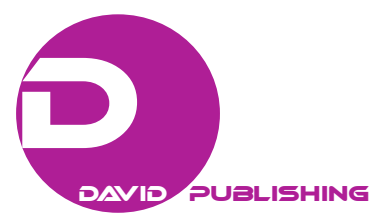

\title{
Water Symbol in Thai Culture in the North West of Vietnam
}

\author{
Dang Thi Oanh \\ LaoCai College of Education, Lào Cai City, Vietnam
}

\begin{abstract}
In this article we study water icons in Thai culture in Northwest Vietnam in terms of: The concept of cultural icon in country, folk literature of the Thai people in Northwest Vietnam; Origins and metabolism of water from cultural icons to Thai folklore; Learn the basic characteristics of water icons in Thai folklore, for example, the basic form of expression in water symbol, the basic meaning and relationships between them; Especially function of water symbol in folklore ethnic Thai in Northwest Vietnam.
\end{abstract}

Keywords: water symbol, Thai culture, Northwest Vietnam

\section{Introduction}

The Thais in Northwest Vietnam have extreme diverse culture. In this cultural treasure, water has a very important role. It is not only the rich resource but also the condition, and basis for the creation of various but unique identity of Thai people.

From a very important role in material life to the spiritual life of the Thais, water has become an sacred object, has the capacity, power protection, purifying, and destruction. It has become the unique symbol in many areas of their cultural life: customs, religion, history, society and arts (language art, sculpture, art, music ...).

\section{Research Tasks and Methods}

\section{Research Tasks}

- Study the concept of cultural icon in the country's northwestern Thailand in Vietnam;

- Find out the origin, the process of transformation of the country from cultural icons to the folklore of the Thai people in Northwest Vietnam;

- Analyze and compare the basic characteristics of water in the symbols of Thai culture in Northwest Vietnam.

\section{Research Methodology}

In this study, we used a combination of the following research methods:

- Interdisciplinary method;

- Methods of ethnographic fieldwork;

- Methods of observation;

- Type of comparison method;

- Methods of analysis. 


\section{Results and Discussion}

\section{Overview Water Symbols in Thai Folk Culture and Literature}

Symbol is an icon that helps us perceive the imperceptiveness. Symbol is interpreted as symbolic images both accepted and widely used by ethnic communities for a long time. The meaning of symbol is various with numerous stages, hidden inside and sometimes elusive.

Water symbol in Thai folklore is the specific symbol, derived from the unique role of water in the life of Thai people to generalize the phenomena, things which have the wider sense but closely related to it. In other words, the symbol of water in Thai culture, is not selected and accepted as it exists in reality in of itself. In contrast, it is accepted to generalize a broader sense, or concept in Thai culture.

Water symbol in Thai folk culture is a language art symbol. It is a way of symbolizing the specific forms of matter: water, rivers, streams, ponds, ditches, etc, in objective reality and the abstract notion of the Thai people's spiritual life through the sound and language system. This transformation is presented unitedly between the visual representation and surface expression (meaning). Water symbol in Thai folk culture is intangible but it can elicit the nature of the phenomena, actions based on the hierarchic stimulation of the imagination to recall the memories of the unconscious mind, enlightened minds in a very flexible way.

\section{An Overview of the Origin and the Transfer Process of Water Symbols From Culture to Thai Folk Culture in the North West of Vietnam}

The origin of water symbols in the cultural icon, Thai folk culture. Generally the origin of the symbols in culture as well as in Thai culture is the living environment; objective reality has existing around human beings. In contrast the icons will also reflect the objective reality even though it is the impulsive perception value filled up with mythical and magic factors.

Metabolism of water from cultural icon to the folk culture. With these insights about the origins of the icon before scientists (Ph.D. Nguyen Thi Ngan Hoa, Vietnam), we applied to learn the metabolism of water in the cultural icons into folklore Thai following diagram (see Figure 1): 


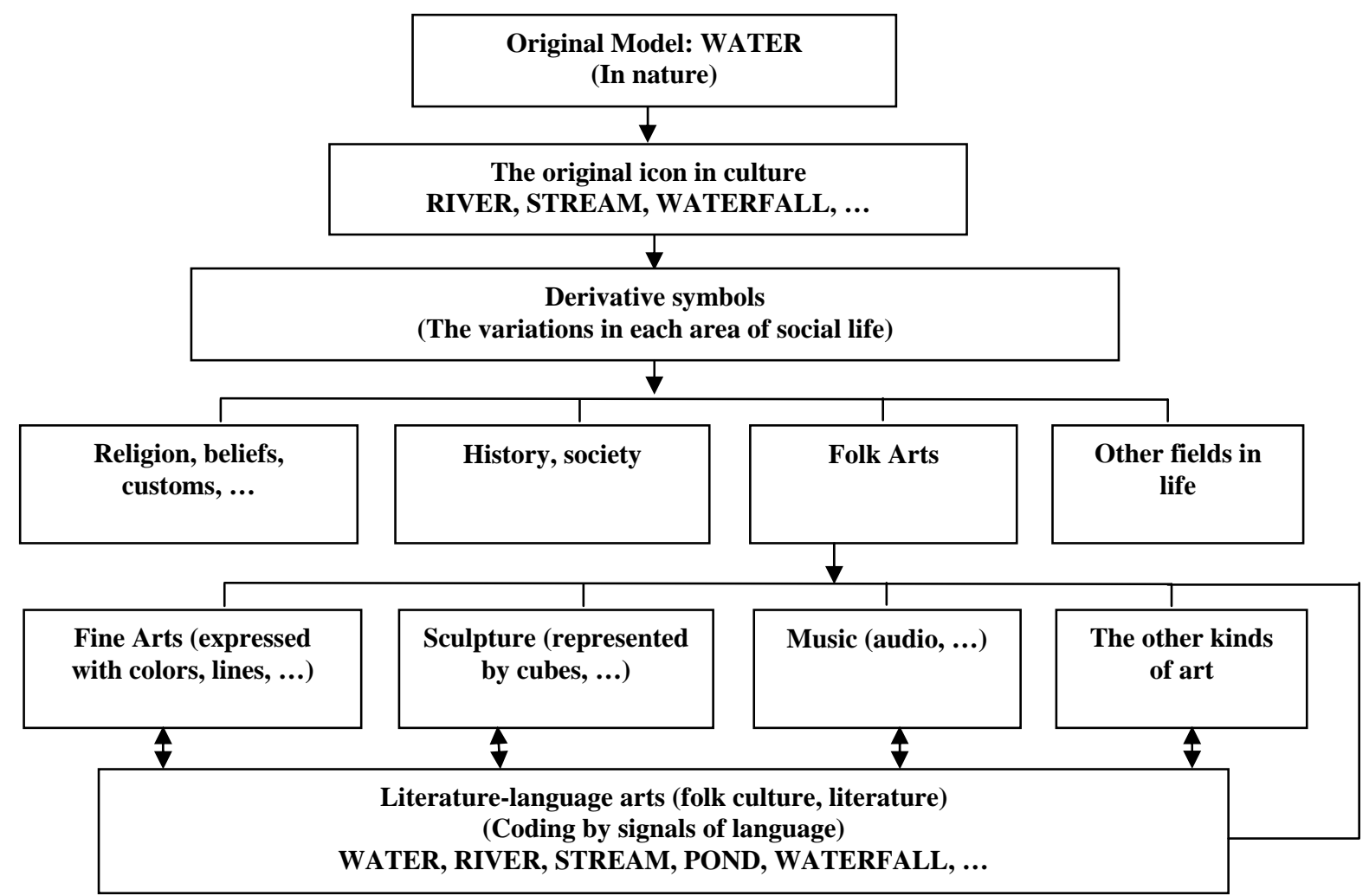

Figure 1. Simulation of the origin and metabolism of water to the water symbols in culture and folk culture.

According to this diagram, it is clear that water symbol in Thai folk culture is one derived aspect of the water symbol from the language art; it plays a meaningful and special role. It is not only an independent dimension but also has a transit function of all the original samples and the original icon, the derivative icon in the different fields of cultural life in an intermediate signal system: the system of language. Therefore, the symbol of Thai folk culture can be a particular level and can be the level which has transit function of water symbol.

Thus, the metabolisms of the water icon from the aspects of culture (religion, beliefs, customs, traditions, music, painting, sculpture ...) into literature icons in general, Thai folk culture in particular is the coding process of concepts by using symbols of language (oral and written). However, the signals of language are not merely the symbols that name things and the phenomena in reality; they are special signals of language to elicit the implied meaning with much larger and more general notions. This transformation is expressed through the unity between the form (description) and the expression (meaning).

Differentiating water symbol from some other kinds of art symbol. The icon is an image, an object, an idea, ... that is exposed to form symbols, to express an abstract sense, but not any pictures, objects, concepts which are also symbols. Therefore it is necessary to distinguish icons with some normal representations of images such as sign language, metaphor, literary ... However, the difference is relative without the clear distinction, because "The symbol is a metaphor used at high-density with conventional nature". 


\section{The Symbols of Water in Thai Folk Culture}

\section{The forms of expression and meaning of water icon.}

The forms of expression of water icon in Thai folk culture. Studying the water symbols in culture, and Thai folk culture, we found that water is a symbol of expression in various forms. Regarding forms of expression, these factors are related to each other by a relationship and work together to represent many unique significances, and artistic values.

Among the ways to express symbols of water, there is always certain relationship, that can be generated relationship. For example, from the stream, Thais block the water flow to horizontal high water thourgh dams in order to run into ditches; then they split the water into smaller lines that flow into the rice fields.

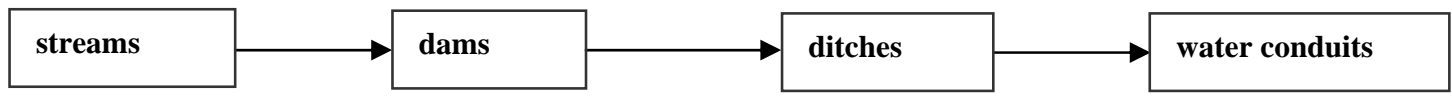

Figure 2. The derivative relationship of the the symbol of water.

\section{The relations division.}

For example, rain water from space, we can be divided into smaller watersources: river, pond, waterfall, water mines, fading, three rivers, streams, ...

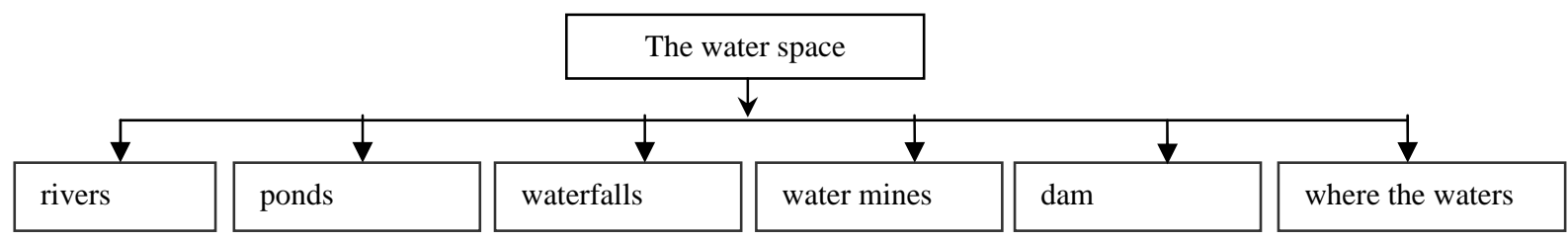

Figure 3. The differentiated and peer relationship of the expression form of the water symbol.

The peer relationships.

For example, forms of expression: Rivers, ponds, waterfalls, mine water, dams, and streams, ... in the diagram above are forms of expression which have the same level: water space.

The contrast relationship.

River is a big watercourse and stream is a small watercourse; flood is of lots of water everywhere opposed to drought with low water, dryness.
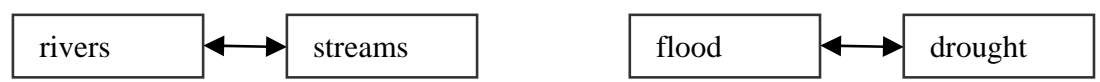

Figure 4. The contrast relationship among the expression forms of water symbol.

Symbolic meaning of water. The meaning of the symbols for Thai folk culture is not constant but variable, and always has the relations between the variables and relations among the folk author and the Thai community.

There is an interactive relationship between the fundamental meaning of the symbol and the meaning in each dimension, and it is materialized in different levels, in each work, that we modeled in the following diagram: 


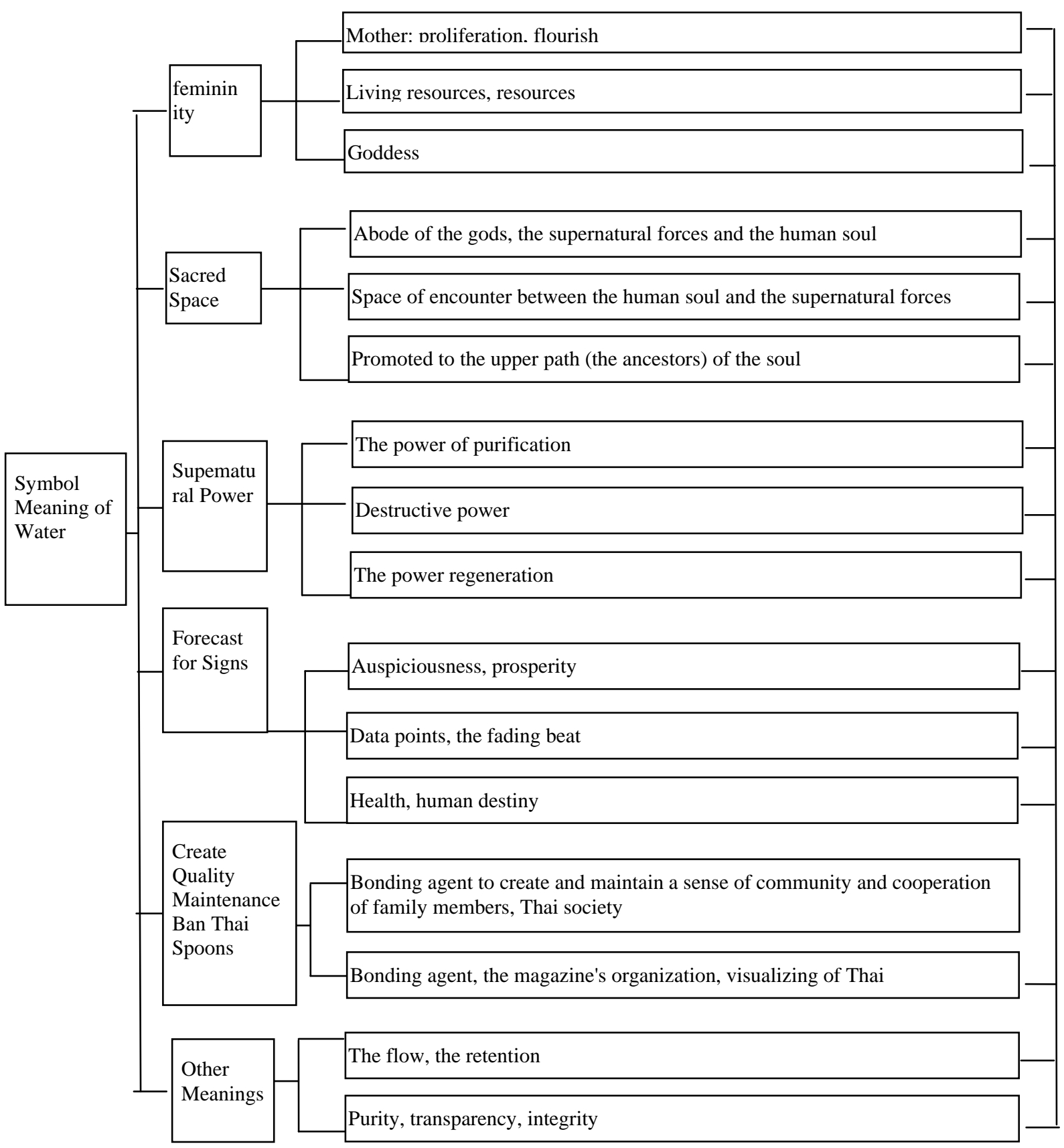

Figure 5. The meaning aspect of water symbols.

Under this scheme, the different definitions share at least one aspect of meaning in a direction that most have the same meaning at least one aspect. Among the features there is close meaning relationship. In every direction that contains sharp contrast meaning, the complex and pairing nature of the water symbol is revealed very clearly in contrast, that makes things and phenomenon descriptions become clear and understandable.

The relationship between forms of expression and the meaning in Thai folk culture has always been connected, and flexible. Each form of expression not only has the basic symbolic meaning but is also capable of extension of connection to represent many different meanings or explanations: 


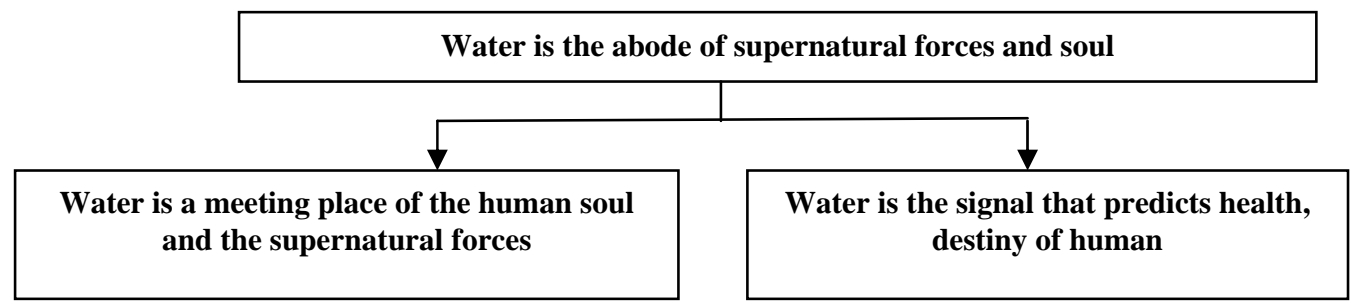

Figure 6. The inter-relationship of meanings in a same meaning direction of water symbol.

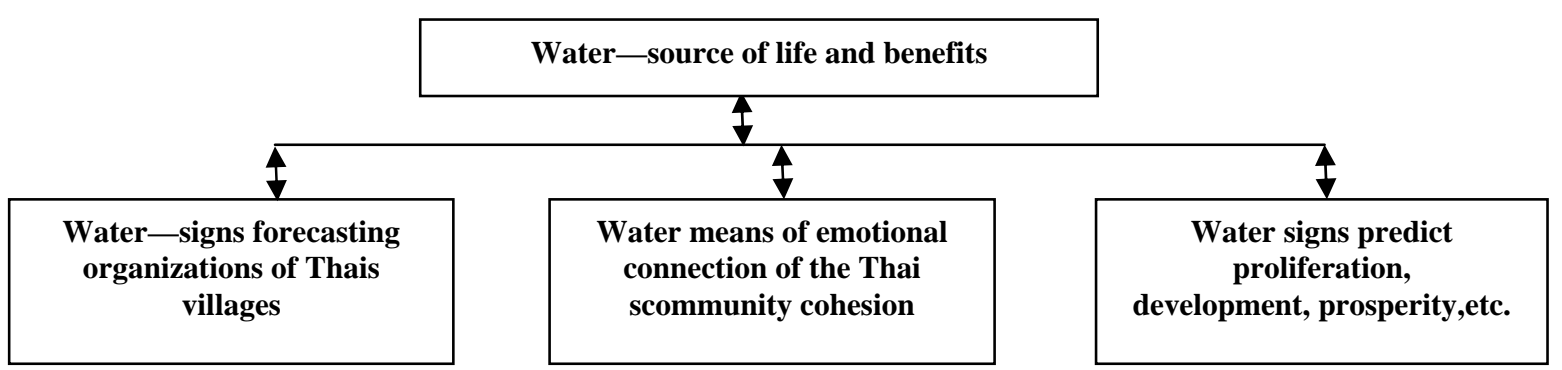

Figure 7. The inter-relationship of meanings in different meaning directions of water symbols.

If the diagram is called the direction of symbolic meaning in the culture, and in Thai folk culture, we will have the lines showing the division of meanings, the meaning directions of the symbol user; the circles indicate the cultural phases (time period); the red one is the original culture in which the icon was born; the next bigger circles are the cultural stages in the process of cultural icons. We see that the meanings, the directions are incredibly rich and diverse. They are linked together by the multi-dimensional relationship: adjacent, mutual, arising... In the process of development, the icon is influenced by the cross-culture of the ethnic groups in the same era and different cultures in different eras (each circle is an age), which help objects to retain their original meanings and continue to have additional features, new meanings or may be dying, death (insignificant).

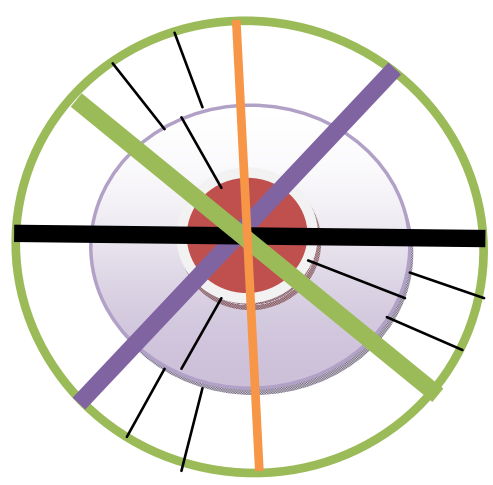

Figure 8 . The direction of water symbol.

The relationship between forms of expression and the meaning of the water symbols. The relationship between forms of expression and the direction of symbolic meaning in the culture, and in Thai folk culture is indirectly based on similar association and it is also consistent, and relational in nature. This relationship exists in all its forms of manifestations and the level of symbolic meaning, creating the penetration and connection between the form and the content, the meaning of this symbol. 
For some forms of expression, the direction of its symbolism is always stable and does not depend on the context. For example, the forms of wharf, dike, ditches, floods, ... Conversely, in some other forms of symbolic expression their meaning orientation is more dynamic, more sensitive: rivers, abyss, the rain...

\section{Characteristics of the water symbol in Thai folklore.}

The dichotomy and bipolarity characteristics of water symbols, expressed in the aspects of form and meaning. Dichotomy and bipolarity case is one of the outstanding characteristics of water symbols in Thai folklore. This feature is manifested in different aspects of water symbols:

First, Dichotomy and bipolarity characteristics of water symbol is shown in the flexible form transformation of water symbol; in state of hot - cold ; nature of solid - liquid.

In terms of meaning, dichotomous and bipolar features of water symbols is also expressed quite unique in some aspects of opposite meanings: water is both the source of life, or self-renewal and the source of death, or destruction; in the sacred nature of life and real time where the daily activities of the Thai community happen.

The Dichotomy and bipolarity characteristics of water symbols in Thai folklore derived from synthetic, perceptive, experienced thinking of the agricultural citizens, especially rice agriculture in Southeast Asia. Living harmoniously with nature, in a magnificent and mysterious world, the ancient Southeast Asian people realized that water, as well as everything in the universe exists in a state of Yin Yang dual, good - bad, black - white. They are not completely positive or negative, only good or bad... For all relationships; this transformation has created a samsara cycle for all the phenomena in the universe.

The dichotomy and bipolarity characteristics manifested in paired tendencies of water symbols.

Water-Fire.

In the minds of Thai people, the fire is the symbol of the destruction of rebirth. With his strength, fire can destroy lives of people and all species but also is the means by which people use to ward off evil spirits, evil beasts to protect human life. Starting from this concept has led to the fire symbol, when entering the Thai folklore, becomes a bipolar symbol like water: It has both destruction and rebirth meaning.

The rebirth of the fire is manifested in different aspects. In Thai folklore, inventing the fire is considered one of the great miracles, marked a turning point in the development of Thai society: from the fresh raw swallow eating, neglected living to cooked food eating, in-the-house living. The occurrence of fire on earth often associated with a motif of gadflies asking for fire. This motif is common in ethnic folk culture of the northern mountainous Thai, Muong, Laos...

Water-Plants.

Water functions as a source of life, growth, development, rebirth of people and things in the universe, in which plant is manifested for this function. In contrast, plant is the source of water: plant helps the soil to retain water in the surface layer from which it stabilizes the underground aquifers; plant is one of the important factors involved in the cycle of water on surface of the earth... So, the relationship between two symbols is often a mutual, supplemented relationship.

Unlike the relationship between water and plants, the relationship between land and water are diverse and abundant, depends on the aspects that they have supplementation, interaction or contrast properties. So, the pair water - land in the Thai folk culture works also covers different meanings: they can supplement meaning to each other or against each other to clarify, highlight the significance of the poetry, literature or the whole works. 
From the concept that land and water are the sources of all lives on Earth, the unknown authors emphasized these two elements in the works of Thai folk culture. They were as the first sketches, basic and indispensable in the picture of life in the early days of earth: From the time the sky was like the fungus / new Land had seven islands / started of nine rivers.

\section{The function of water symbol in Thai folk culture.}

The function of symbol water in the building of characters in Thai folk culture works. Starting from awareness of many similarities between water and women about the appearances and personalities, some Thai folk culture works have used the space water (rivers, streams, etc.) to describe the soft beauty and gentle personality of the female characters, especially the girls.

Particularly, when studying how to build the giant characters of Thai folklore, it is clearly seen that water and water-related activities of Thai people have very important role in depicting shapes, personalities, victories of the characters. Such character like "Ai Lac Cac" had a giant appearance that he took the "it” out to brandish fish from the Da River upstream. Then, his wife caught fish with her dress in the downstream of this river. When the "it" was crashed by a paddle of wood, after being removed out, this paddle of wood can be carved into a large boat for seven people rowing.

For normal characters, when portraying their personalities and talents in each particular situation, the authors also used space water (rivers, streams, ponds, lakes, waterfalls, etc.) or the status and nature of water (clear, smooth ...). In folk songs and folk music, water is also the symbolic object, a scale to measure affection among human: If two people love each other, they ladle water into the basket and also have time to eat dinner / If not, even the water ladled into the big jar also leak out.

With the characters that are animals that living in water such as turtles, Nagas, fish, crabs, ... symbol water also contributed significant role in building character, portraying appearance (some tales like Noi oan tinh o ban nuoc chui lo, Moi tinh Bo Bua, Cau chuyen Bang Tong, Noong Phu...).

The function of symbol water in the creation of types and the basic motifs in Thai folklore. In the Thai folk stories, the types and motifs related to water appear quite common and play very important role in creating the content and value of works. Types can be considered as the types of stories: narrative style with the main character is a turtle, Naga, narrative style about the deluge: Drought and deluges, U Va lake, deluge and the gadfly searching for fire, deluge, etc.; the stories explaining the characteristics of rivers and streams: U Va Lake, the legend of Hong Cum, Hong Ma Nao, Tong Khao, ...

Among the motifs related to water, the meaning of water symbol has an significant role. The meaning of water - the sacred space help to create motifs: the main character of the story after his or her death in the water turned into the aquatic animal; people who met the legendary characters in the water and these characters help to make the life better... From the meaning of water destruction to earth, all things have contributed to create some motifs: water filling the earth and all creatures die; drought, water in rivers, streams, lakes dried up, withered trees die, and so on.

The function of symbol water with language and plot. In Thai folk culture, the vocabulary system about water are abundant, including words describe the space, nature, characteristics, activities of water, the fishery production activities related to water, the underwater flora and fauna. Such words in the water space, including rivers, streams, ponds, waterfalls, swamps, pools, water sources; the nature of water like water, rain, hail, snow, fog, hot water, steam, bubble, flood, drought. The vocabularies in this system are related to each other and work 
together to represent the significance of water symbol and the value of folk culture works.

As the types, motifs, language, plot building in the Thai folk stories also shows important contribution of water symbol. There are many stories whose subjects and objects are described by rivers and streams. For instance, stories about the Nam Ron river explain its name came from the fact that, this river, in the old days, had wood at its upstream. The Nam Nua river got its name because there are many co nua trees (si) growing by the river bank at its upstream.

\section{The function of symbol water with the space-time in the work of art.}

Art space.

In the sense of sacred space, destruction and regeneration, much water space in the works of Thai folk culture is considered as the space containing the life and activities of the characters. For example, in Tired Pha story, the river is the main space where main character's activities take place Pha Met: The river is the boundary between the coziness, union of family with their separation; the river is the place that challenges and witnesses Pha Met's sadness and his longing for his wife and children; the river is the place of gathering of brave, faithful people and is the burial place of the greedy, cunning people.

Since water is a signal of the Thai villages, the water space in works of Thai folk culture has become the performing arts space describes specific characteristics of residential areas or villages - where the brothers, relatives, neighbors get together. It can be said that no matter how far the water flow, the space of actions, villages and stories extends there.

Art time.

In the works of Thai folk culture, the meaning of water symbol also contributes to art time. For instance, the perception about water of people at different stages in life marks the changes, the transitions in the life of a person. In proverbs, time is portrayed by the characteristics of the water in each season (shallow water: the dry season, flood water: the rainy season) and early season rains signal the growing season.

We can say, as a unique art form, water symbol has close link with other art elements in the folk culture works. It helped the art form of the work more diverse and effective in the expression of ideological content.

\section{Conclusion}

Thus, water symbol is a significant symbol of Thai culture and literature. The way water symbols of different fields of cultural life becomes the water symbol in Thai folk culture in particular and Vietnamese culture in general is the way the language, which is encoded by the concept of water in many aspects of cultural life comes into the works based on the rules of artistic language reflections.

In verbal art forms (literature), the water symbols has many characteristics dominated by folk culture genres: dichotomous characteristics and parallel tendency are rather have popular. In contrast, the water symbol also has impact on the art elements such as characters, motifs, plot, art space and time, etc. and thus creates the value of at content of literary works.

\section{References}

Oanh, D. T. (2010a). Muòng Then legend. Hanoi: Ethnic Culture.

Oanh, D. T. (2010b). Water symbol from folklore wisdom of Thai Đen group in former Dien Bien. Hanoi: Times.

Oanh, D. T. (2011). Thai culture—Folk knowledge. Hochiminh: The Youth. 